\title{
CD44-Targeting Oxygen Self-Sufficient Nanoparticles for Enhanced Photodynamic Therapy Against Malignant Melanoma
}

This article was published in the following Dove Press journal: International Journal of Nanomedicine

\author{
Xiaoyang Hou ${ }^{1, *}$ \\ Yingkai Tao',* \\ Xinxin $\mathrm{Li}^{\mathrm{l}}, *$ \\ Yanyu Pang' \\ Chunsheng Yang $\mathbb{D}^{2}$ \\ Guan Jiang $\mathbb{D}^{\prime}$ \\ Yanqun Liu' \\ 'Department of Dermatology, The \\ Affiliated Hospital of Xuzhou Medical \\ University, Xuzhou 221002, People's \\ Republic of China; ${ }^{2}$ Department of \\ Dermatology, The Affiliated Huai'an \\ Hospital of Xuzhou Medical University, \\ The Second People's Hospital of Huai'an, \\ Huai'an 223002, People's Republic of \\ China \\ *These authors contributed equally to \\ this work
}

Correspondence: Guan Jiang; Yanqun Liu Department of Dermatology, The Affiliated Hospital of Xuzhou Medical University, 99 West Huai Hai Road, Xuzhou, Jiangsu 221002, People's Republic of China

Email dr.guanjiang@xzhmu.edu.cn; xyfylyq@sohu.com
Objective: Nanotechnology-based photodynamic therapy (PDT) is a relatively new antitumor strategy. However, its efficacy is limited by the hypoxic state in the tumor microenvironment. In the present study, a poly(lactic-co-glycolic acid) (PLGA) nanoparticle that encapsulated both IR820 and catalase (CAT) was developed to enhance anti-tumor therapy. Materials and Methods: HA-PLGA-CAT-IR820 nanoparticles (HCINPs) were fabricated via a double emulsion solvent evaporation method. Dynamic light scattering (DLS), transmission electron microscopy (TEM), laser scanning confocal microscopy, and an ultraviolet spectrophotometer were used to identify and characterize the nanoparticles. The stability of the nanoparticle was investigated by DLS via monitoring the sizes and polydispersity indexes (PDIs) in water, PBS, DMEM, and DMEM+10\%FBS. Oxygen generation measurement was carried out via visualizing the oxygen bubbles with ultrasound imaging system and an optical microscope. Inverted fluorescence microscopy and flow cytometry were used to measure the uptake and targeting effect of the fluorescent-labeled nanoparticles. The live-dead method and tumor-bearing mouse models were applied to study the HCINP-induced enhanced PDT effect.

Results: The results showed that the HCINPs could selectively target melanoma cells with high expression of CD44, and generated oxygen by catalyzing $\mathrm{H}_{2} \mathrm{O}_{2}$, which increased the amount of singlet oxygen, ultimately inhibiting tumor growth significantly.

Conclusion: The present study presents a novel nanoplatform for melanoma treatment.

Keywords: catalase, hyaluronic acid, IR820, photodynamic therapy, tumor hypoxia

\section{Introduction}

Photodynamic therapy (PDT) is a regulatory approved treatment that causes little trauma and few side effects, and is highly controllable. It has been applied to treat various diseases, including malignant tumors. ${ }^{1,2}$ PDT relies on a specific wavelength of excitation light to irradiate a photosensitizer in the presence of molecular oxygen, producing singlet oxygen, which causes apoptosis or necrosis of tumor cells. $^{3,4}$ Conventional photosensitizers, such as porphyrins and their derivatives, have certain shortcomings, including long half-life, poor water solubility, and short activation wavelength, leading to poor tissue penetration, which limits their clinical application. $^{3,5}$ Near-infrared (NIR) fluorescent dyes have been studied recently because of their excellent fluorescence imaging capability and their outstanding performance in photothermal therapy (PTT) and PDT. Properties such as amphipathy, minimal interfering absorption and fluorescence from surrounding tissue, and 
the NIR region excitation wavelength for good tissue penetration make them potential photosensitizers. ${ }^{6,7}$ IR820, a cyanine dye that can be used for fluorescence imaging, PTT, and PDT, has a similar chemical structure to indocyanine green (ICG) (Scheme 1), but with better in vitro and in vivo stability, which may be attributed to the addition of a chlorinated cyclohexene as an intermediate ring. ${ }^{8-10}$ Under NIR laser irradiation, IR820 produces singlet oxygen to kill tumor cells, making it a promising candidate for PDT. ${ }^{11}$ Further modification can increase the yield of singlet oxygen and improve the efficacy of PDT. Zhou et al constructed a theranostic platform via grafting IR820 onto the surface of ferroferric oxide nanoparticles with a 6-amino hexanoic acid linker, which significantly increased singlet oxygen production. ${ }^{12}$

The hypoxic state in the tumor microenvironment, originating from the rapid metabolism of tumor cells and inadequate oxygen supply, is another factor restricting PDT's efficacy. ${ }^{13}$ Consequently, various methods to improve oxygen levels and reverse hypoxia in tumors have been attempted. For example, Cheng et al loaded a photosensitizer into perfluorocarbon nanodroplets, which could maintain a higher oxygen content than the tumor microenvironment to achieve oxygen self-enriching PDT. ${ }^{14}$ Guo et al encapsulated hemoglobin and ICG into liposomes, which effectively delivered oxygen to the

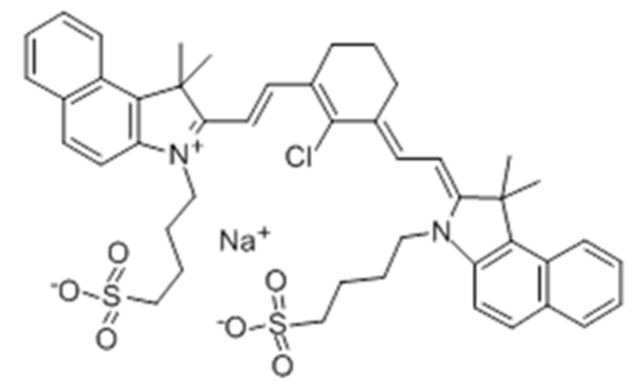

IR820

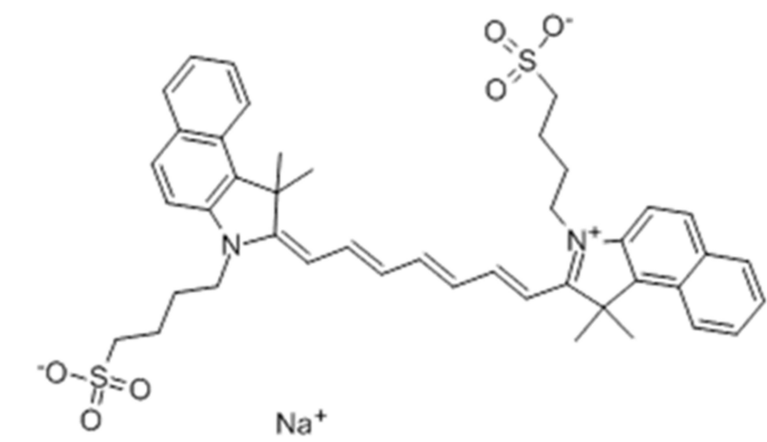

ICG
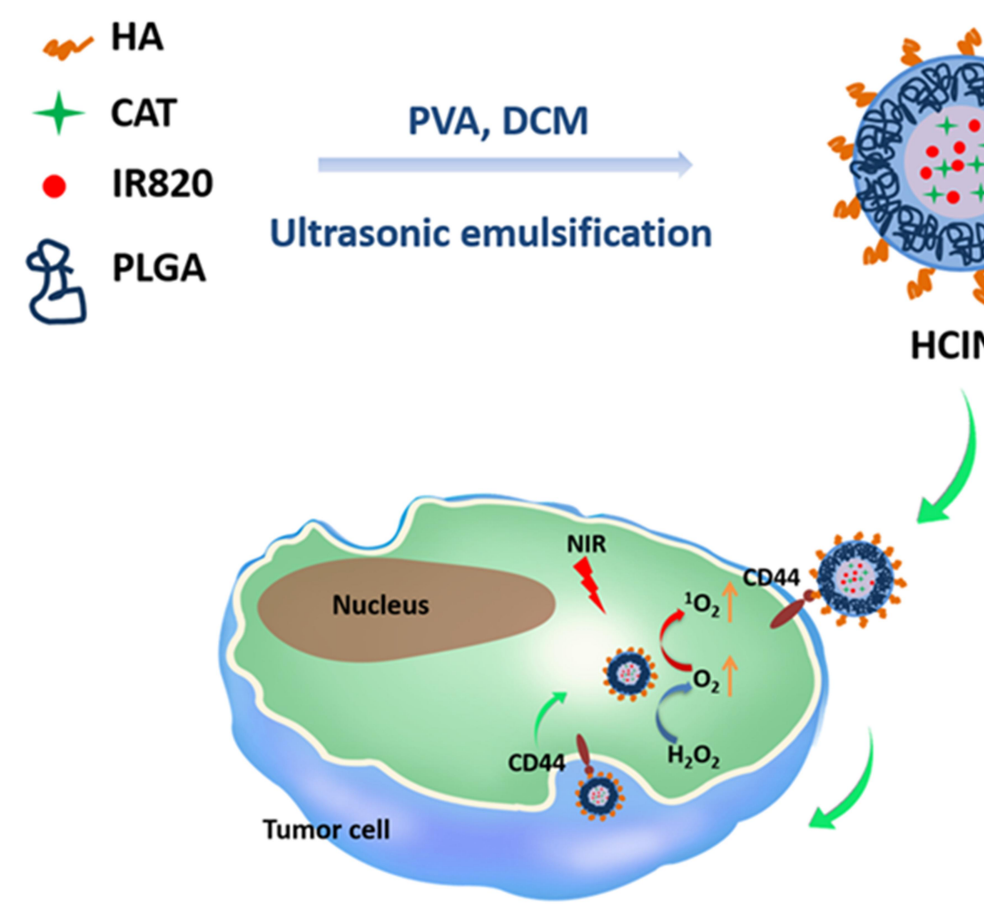

Scheme I Schematic illustration of the HCINP assembly and structure, and the mechanism of enhanced PDT efficacy for tumor treatment. 
tumor, alleviated hypoxia, and increased reactive oxygen species (ROS) for PDT. ${ }^{15}$ Unfortunately, the oxygencarrying stability of the drugs and their oxygen-release efficiency in the tumor remain a challenge. There is more $\mathrm{H}_{2} \mathrm{O}_{2}$ in tumors (at concentrations of $100 \mu \mathrm{M}-1 \mathrm{mM}$ ) compared with that in normal tissues; thus representing a suitable resource pool to increase the tumor oxygen content. ${ }^{16}$ Catalase (CAT) efficiently generates oxygen by catalyzing $\mathrm{H}_{2} \mathrm{O}_{2}\left(\mathrm{CAT}: \mathrm{H}_{2} \mathrm{O}_{2}=1: \sim 1,000,000\right)$, increasing the local oxygen concentration of the tumor and regulating tumor hypoxia. ${ }^{17}$ However, free CAT is easily deactivated by proteases in vivo, making its accumulation inside tumors difficult and limiting oxygen production. ${ }^{17}$

Nanotechnology might solve the inherent problems of photosensitizers and CAT in terms of biological stability and targeting. Encapsulating them inside nanocarriers can isolate them from molecules in the body, thus improving their stability without affecting their functions. Poly(lacticco-glycolic acid) (PLGA) is an FDA-approved polymer with excellent biocompatibility, biodegradability, and easy modification that is widely used to construct nanomedicines. ${ }^{18,19}$ In the present study, we incorporated IR820 and CAT into PLGA nanoparticles. To improve their ability to target tumor cells, hyaluronic acid (HA) was modified on the surface of the nanoparticles to construct HA-PLGA-CAT-IR820 nanoparticles (HCINPs). Tumor cell internalization of the HCINPs would result in CAT catalyzing $\mathrm{H}_{2} \mathrm{O}_{2}$ to produce oxygen in the cells to overcome tumor hypoxia. IR820 then converts oxygen into singlet oxygen under irradiation by an NIR laser, thereby enhancing PDT (Scheme 1). This study provides a new approach to relieve tumor hypoxia and to improve IR820based PDT against malignant melanoma.

\section{Experimental Methods}

\section{Materials}

PLGA (lactide/glycolide $=50: 50, \mathrm{Mw}=10,000 \mathrm{Da}$ ) was purchased from Xi'an Ruixi Biological Technology Co., Ltd (Xi'an, China). Poly (vinyl alcohol) (PVA, average $\mathrm{Mw}=$ 30,000-70,000 Da), IR820, and CAT were acquired from Sigma-Aldrich (St. Louis, MO, USA). HA (Mw = 10,000 Da) was purchased from Dalian Meilun Biotechnology Co., LTD (Dalian, China). Coumarin-6 was purchased from Beijing Solarbio Science \& Technology Co., Ltd (Beijing, China). The HA ELISA Kit was purchased from Wuhan Fine Biotech Co., Ltd (Wuhan, China). Tris (4,7-diphenyl1,10-Phenanthroline)ruthenium(II) dichloride complex
$\left[\left(\mathrm{Ru}(\mathrm{dpp})_{3}\right)\right] \mathrm{Cl}_{2}$ was acquired from Alfa Aesar (Tewksbury, MA, USA). The anti-CD44 antibody was purchased from Proteintech (Chicago, IL, USA). The anti-hypoxia inducing factor 1 alpha (HIF-1 $\alpha$ ) antibody was purchased from Immunoway Biotechnology (Newark, DE, USA). The carbonic anhydrase IX (CAIX) antibody was purchased from Abcam (Cambridge, UK). All other chemical reagents were of analytical grade and were used without further purification.

\section{Synthesis of HA-PLGA-CAT-IR820 Nanoparticles}

We prepared HCINPs using a double emulsion solvent evaporation method with modifications. ${ }^{20}$ Briefly, $1 \mathrm{mg}$ of CAT and IR820 were dissolved in $0.2 \mathrm{~mL}$ of $1 \%$ PVA. The mixture was then added to $5 \mathrm{mg} / \mathrm{mL}$ PLGA in dichloromethane solution and subjected to phacoemulsification in an ice bath to obtain the primary emulsion. The primary emulsion was added drop-wise to $10 \mathrm{~mL}$ of $2 \%$ PVA containing $0.5 \mathrm{mg}$ HA. The obtained solution was further emulsified using a sonicator. The homogeneous emulsion was stirred at room temperature overnight to devolatilize the organic solvent. The resulting nanoparticles were collected by centrifugation and washed three times with ultrapure water.

HA-PLGA-CAT nanoparticles (HCNPs), PLGA-CATIR820 nanoparticles (CINPs), and HA-PLGA-IR820 nanoparticles (HINPs) were also synthesized using a similar method, but without IR820, HA, or CAT, respectively. To study their uptake and intracellular localization, HCINPs were labeled with coumarin-6, a green hydrophobic fluorescent dye (excitation wavelength $=466 \mathrm{~nm}$ and emission wavelength $=504 \mathrm{~nm}$ ).

\section{Characterization}

The morphology of the HCINPs was observed using transmission electron microscopy (TEM) (Tecnai G2 Spirit Twin). The hydrodynamic diameter, polydispersity index (PDI), and zeta potential distribution were measured using dynamic light scattering (DLS, Malvern Analytical, Malvern, UK). The nanoparticles' absorption spectra were determined using an UV-Visible/NIR Spectrophotometer (PerkinElmer, Waltham, MA, USA). To identify successful HA modification on the nanoparticle surface, fluorescein isothiocyanate (FITC) and di-alkyl indocarbocyanine (DiI) were used to label HA and CINPs, respectively, and then the nanoparticles were observed using a confocal laser scanning microscopy (CLSM, Olympus, Japan). 


\section{Stability of HCINPs}

The long-term stability of HCINPs in water was monitoring via their hydrodynamic diameter and PDI on day 0,3 , $6,9,12$, and 15 . To detect the dispersibility of the nanoparticles in different media, we measured the particle size of HCINPs stored in PBS, Dulbecco's modified Eagle's medium (DMEM), DMEM+10\% FBS for 0, 24, and 48 $\mathrm{h}$. The drug release experiment was performed by placing HCINPs aqueous solution on a shaking table at room temperature for $48 \mathrm{~h}$. The free IR820 or CAT content in the solutions were determined at different time points $(0$, $1,3,12,24$, and $48 \mathrm{~h}$ ).

\section{Cell Culture}

Human melanoma cell lines (MV3, M14, and A375) were purchased from Shanghai Cell Collection (Shanghai, China), and human skin fibroblast cells (HSFs) were purchased from Bena Culture Collection (Jiangsu, China). The cells were routinely cultured in DMEM containing $10 \% \mathrm{FBS}, 100 \mathrm{U} / \mathrm{mL}$ penicillin, and $100 \mu \mathrm{g} / \mathrm{mL}$ streptomycin. The cells were then cultured in a $5 \% \mathrm{CO}_{2}$-saturated humidity incubator at $37^{\circ} \mathrm{C}$.

\section{Measurement of CD44 Expression in Melanoma Cells}

The expression levels of CD44 in HSF and melanoma cells (MV3, M14, and A375) were detected using quantitative real-time reverse transcription PCR (qRT-PCR) and immunofluorescence.

Total RNA extraction was performed from cells using the Trizol Reagent. After quantification, equal amounts of RNA samples were reverse-transcribed to cDNA according to the manufacturer's instructions. The cDNA were then analyzed using quantitative real-time PCR (StepOne real-time PCR system, Applied Biosystems, Carlsbad, CA, USA) using SYBR green as fluorescence dye. CD44 primers: Forward: 5'-GAAGAAAGCCAGTGCGTCTC-3'; Reverse: 5'-GTGCTCTGCTGAGGCTGTAA-3'. GAPDH primers: Forward: 5'- GGAGCGAGATCCCTCCAAAAT3'; Reverse: 5'- GGCTGTTGTCATACTTCTCATGG -3'.

HSF and MV3 cells were seeded in glass bottom cell culture dishes at $1.5 \times 10^{5}$ cells per dish and incubated overnight. After washing with PBS, the cells were fixed with $4 \%$ paraformaldehyde, and permeabilized with $0.5 \%$ Triton X-100. The cells were blocked with $0.5 \%$ bovine serum albumin for $30 \mathrm{~min}$ at $37{ }^{\circ} \mathrm{C}$, and then incubated with anti-CD44 primary antibodies at $4{ }^{\circ} \mathrm{C}$ overnight.
Alexa Fluor 488-labeled goat anti-rabbit IgG $(\mathrm{H}+\mathrm{L})$ was then added to the cells and incubated for $1 \mathrm{~h}$ at $37^{\circ} \mathrm{C}$. Finally, the cell nuclei were stained using 2-(4-amidinophenyl)-1H-indole-6-carboxamidine (DAPI) for $5 \mathrm{~min}$ at room temperature, and then imaged under CLSM.

\section{Cell Counting Kit-8 (CCK-8) Assay for Cytotoxicity Detection}

The CCK-8 assay was performed to assess the cytotoxicity of HCINPs. Briefly, HSF and MV3 cells were seeded in 96-well plates at $3 \times 10^{3}$ cells per well and incubated overnight, before being treated with different concentrations of HCINP for $24 \mathrm{~h}$. The CCK- 8 reagent was added according to the manufacturer's instructions. The plates were incubated at $37^{\circ} \mathrm{C}$ for $2 \mathrm{~h}$, and the absorbance was measured at $450 \mathrm{~nm}$ using a microplate reader (BioTek, Winooski, VT, USA).

\section{Cellular Uptake and Intracellular Localization of HCINPs in Cells}

Inverted fluorescence microscopy (Olympus IX71, Japan) was utilized to measure the cellular uptake of HCINPs labeled with coumarin-6. Briefly, MV3 cells were seeded in 6-well plates at a density $2 \times 10^{5}$ cells per well and incubated overnight. After $6 \mathrm{~h}$ of incubation with $0,4,8$, and $16 \mu \mathrm{g} / \mathrm{mL}$ of HCINPs, respectively, cells were washed with PBS and fixed with 4\% paraformaldehyde. DAPI was used for nuclear staining, and images were taken under an inverted fluorescence microscope.

MV3 cells were seeded in a glass bottom cell culture dish at $1.5 \times 10^{5}$ cells and incubated overnight. The cells were then exposed to $8 \mu \mathrm{g} / \mathrm{mL}$ of HCINPs for different times (1, 3, 6, and $12 \mathrm{~h})$, and washed with PBS. Next, the cells were incubated with Lyso Tracker Red (60 nM) for $1 \mathrm{~h}$ at $37{ }^{\circ} \mathrm{C}$ following the supplier's protocol. Images were taken under CLSM.

\section{Targeting Ability Measurement}

Determination of the comparative uptake of HCINPs by HSF and MV3 cells by inverted fluorescence microscopy was carried out as above except that the dosage of HCINPs was $8 \mu \mathrm{g} / \mathrm{mL}$.

Free HA and CD44 antibodies were used to further demonstrate the targeting ability of HA. Briefly, MV3 cells were seeded in 6 -well plates at a density $2 \times 10^{5}$ cells per well and incubated overnight. The cells were preprocessed by free HA $(1 \mathrm{mg} / \mathrm{mL})$ or CD44 antibody $(20 \mu \mathrm{L} / \mathrm{mL})$ for 
$4 \mathrm{~h}$. After washing with PBS, $16 \mu \mathrm{g} / \mathrm{mL}$ CINPs or HCINPs were added for another $4 \mathrm{~h}$ incubation. After nuclear staining with DAPI, the cells were detected under an inverted fluorescence microscope.

\section{Oxygen Generation Measurement}

HINP and two replicates of the HCINP solution at $8 \mu \mathrm{g} / \mathrm{mL}$ were prepared, and $\mathrm{H}_{2} \mathrm{O}_{2}$ at a final concentration of $100 \mu \mathrm{M}$ was added to the HINPs and one HCINP solution. The three solutions were incubated for $1 \mathrm{~h}$ at $37^{\circ} \mathrm{C}$, and the generation of bubbles in the three solutions were observed and photographed using an ultrasound imaging system (Siemens, Munich, Germany) and an optical microscope.

MV3 cells were seeded in 6-well plates at $2 \times 10^{5}$ cells per well and incubated overnight. The cells were preprocessed with $2 \mu \mathrm{M}\left[\mathrm{Ru}(\mathrm{dpp})_{3}\right] \mathrm{Cl}_{2}$ for $4 \mathrm{~h}$ and further incubated with 0,4 , and $8 \mu \mathrm{g} / \mathrm{mL}$ HCINPs for $12 \mathrm{~h}$. The cells were washed three times with PBS and image under an inverted fluorescence microscope.

\section{Live/Dead Cell Double Staining Assay}

The experiment was carried out according to a previously described method. ${ }^{12}$ MV3 cells were exposed to IR820 (8 $\mu \mathrm{g} / \mathrm{mL})$, CINPs $(8 \mu \mathrm{g} / \mathrm{mL})$, HINPs $(8 \mu \mathrm{g} / \mathrm{mL})$, and HCINP $(8 \mu \mathrm{g} / \mathrm{mL})$ for $12 \mathrm{~h}$. The power density of the $808 \mathrm{~nm}$ NIR laser was $4 \mathrm{~W} / \mathrm{cm}^{2}$ for $5 \mathrm{~min}$.

\section{Tumor Xenografts and Anti-Tumor Therapy}

All animals used in this study were handled in accordance with the Guide to Laboratory Animal Ethics Examination of Xuzhou Medical University (Animal ethics approval number:201811w002). BALB/c nude female mice at 6-8 weeks old, with bodyweights of 19-21 g, were purchased from the Animal Center of Xuzhou Medical University, Xuzhou, China. Nude mice were housed at constant temperature $\left(22-25{ }^{\circ} \mathrm{C}\right)$ and constant humidity without a specific pathogen level barrier system. Sterilized standard feed and water were provided to the animals.

Tumor-bearing mice were prepared by subcutaneous injection of $4 \times 10^{7} \mathrm{MV} 3$ cells into the selected positions of the mice. When the tumor grew to $200-400 \mathrm{~cm}^{3}$, the mice were randomly divided into seven groups, each containing five members: Group 1: Control (Ctr); group 2: NIR; group 3: HCINPs; group 4: IR820+NIR; group 5: CINPs+NIR; group 6: HINPs+NIR; and group 7: HCINPs+NIR. The drugs at the same concentration $(1 \mathrm{mg} / \mathrm{kg})$ in group 3-7 were intravenously injected into the mice. After $24 \mathrm{~h}$, the tumors in group 2 and groups 4-7 were irradiated with an $808 \mathrm{~nm}$ NIR laser at $4 \mathrm{~W} / \mathrm{cm}^{2}$ for $5 \mathrm{~min}$. The tumor size and body weight were measured for two consecutive days, and the tumor volume was calculated as: Tumor volume $\left(\mathrm{mm}^{3}\right)$ $=$ long diameter $\times$ short diameter ${ }^{2} / 2$. After 14 days, all mice were sacrificed and their main organs (heart, liver, spleen, lung, and kidney) were dissected for pathological biopsy.

\section{In vivo Targeting Effect Analysis of HCINPs}

$\mathrm{BALB} / \mathrm{c}$ nude female mice were inoculated subcutaneously with $4 \times 10^{7} \mathrm{MV} 3$ cells. When the tumor grew up to $700 \mathrm{~mm}^{3}$, the tail veins were injected with fluorescently-labeled CINPs $(1 \mathrm{mg} / \mathrm{kg})$ and HCINPs $(1 \mathrm{mg} / \mathrm{kg})$. The nude mice were sacrificed through cervical dislocation after $24 \mathrm{~h}$. The organs were dissected and fluorescence images were captured using an in vivo imaging system (NightOWL II, LB983, Berthold, Germany).

\section{Detection of HIF-I $\alpha$ and CAIX in Tumor Tissues}

Tumor-bearing mice models were constructed, and the nude mice were randomly divided into three groups with three members each: Group 1: Control (Ctr); group 2: HINPs; group 3: HCINPs. The drugs at the same concentration $(1 \mathrm{mg} / \mathrm{kg})$ were injected through the tail vein. After $24 \mathrm{~h}$, the tumors were dissected out for immunohistochemical analysis and immunofluorescence assays to detect the HIF- $1 \alpha$ and CAIX levels in tumor tissues.

\section{Statistical Analysis}

All results are expressed as the mean \pm standard deviation (SD). One-way ANOVA was performed to compare differences among multiple groups. $\mathrm{P}<0.05$ was considered statistically significant.

\section{Results}

\section{Preparation and Characterization}

HCINPs were fabricated via a double emulsion solvent evaporation method. ${ }^{20}$ CAT and IR820 were incorporated into PLGA nanoparticles, which were coated with HA (Scheme 1). The encapsulation efficiencies of IR820, CAT, and HA in HCINPs were $70.8 \%, 19.5 \%$, and $12.4 \%$, respectively. TEM characterization of the HCINPs' morphology (Figure 1A) showed that the nanoparticles were monodisperse, with an average size of $121.8 \mathrm{~nm}$ and 
a distinct core-shell structure. DLS showed that the average hydrodynamic diameter and PDI value of HCINP were $187.4 \mathrm{~nm}$ and 0.125 , respectively (Figure 1B). The zeta potential of HCINP was $-16.3 \mathrm{mV}$ (Figure 1C). This negative surface charge will contribute to the long circulation and biocompatibility of the nanoparticles. ${ }^{21}$ The UV-Vis /NIR absorption spectrum revealed that the HCNPs had no absorption peak in the range of 400-1000 nm, while HCINP had peaks at $740 \mathrm{~nm}$ and $830 \mathrm{~nm}$, reflecting the encapsulation of IR820 (the absorption peak of CAT in aqueous solution is $230 \mathrm{~nm}$ ) (Figure 1D). To assess the HA modification on the nanoparticles, we used the red fluorescent probe DiI and the green fluorescent probe FITC to label the nanoparticles and HA, respectively. The CLSM results showed that green HA-FITC overlapped with the red DiInanoparticles to produce a yellow color (Figure 1E), thus HA was successfully modified onto the nanoparticles.

\section{Stability Measurement}

In vitro stability of the HCINPs is a major concern for their biomedical application. We determined their stability in aqueous solution for up to two weeks and observed no significant change in their hydrodynamic diameter and PDI, indicating good stability and uniform dispersion (Figure 2A). Equal amounts of HCINP were then added to PBS, DMEM, and DMEM $+10 \%$ FBS to simulate the nanoparticles' state in different physiological environments. HCINPs dissolved in PBS and DMEM showed a slight increase in hydrodynamic diameter, while those in DMEM $+10 \%$ FBS had a particle size similar to that in water (Figure 2B). In addition, the size of the HCINPs in these three solutions did not change significantly within $48 \mathrm{~h}$. These results suggested that the as synthesized HCINPs were stable, favoring their subsequent in vitro and in vivo applications. Drug release experiments showed that IR820 released about $10 \%$ at $48 \mathrm{~h}$, while there was no significant leakage of CAT (Figure S1). This further verified the good stability of the HCINPs.

\section{CD44 Expression and Cytotoxicity Measurement}

CD44 expression is upregulated in cutaneous melanoma tissues. ${ }^{22}$ However, its expression in melanoma cell lines is unclear. Therefore, we determined the expression of CD44 in MV3, M14, and A375 cells, with HSF cells as controls. Compared with that in HSF cells, CD44 was overexpressed in all three melanoma cells, with the highest in MV3 ( 4.2-fold higher) (Figure 3A). Immunofluorescence experiments confirmed that CD44 levels were increased in MV3 cells and was mainly distributed in the cell membrane (Figure 3B). Therefore, we used MV3 cells as a model cell line for subsequent experiments.

CCK-8 assays were performed to determine the cytotoxicity of HCINP toward HSF and MV3 cells (Figure 3C and D). At $0-8 \mu \mathrm{g} / \mathrm{mL}$, the HCINP nanoparticles caused no obvious cytotoxicity to HSF and MV3 cells. At a higher concentration, cell viability decreased slightly, which might have been caused by the residual organic solvent and PVA; however, cell viability remained above $90 \%$.

\section{Uptake and Intracellular Localization}

Coumarin-6, a commonly used green fluorescent probe, was encapsulated in the nanoparticles to study their uptake and intracellular localization in tumor cells. After $6 \mathrm{~h}$ of exposure, significant HCINP uptake by MV3 cells was observed using an inverted fluorescence microscope (Figure 4A), and the cellular internalization increased in an HCINP concentration-dependent manner in the selected range.

The intracellular localization of the nanoparticles was investigated using CLSM. After exposure to HCINPs for 6 h, MV3 cells were dyed with lysotracker (red) to mark lysosomes. The nanoparticles (green) overlapped with lysosomes (red) to present a yellow color, indicating colocalization of HCINPs in intercellular lysosomes (Figure 4B). This result indicated that HCINPs, internalized via CD44-mediated endocytosis, entered tumor cell lysosomes. ${ }^{23}$ Furthermore, we studied the localization of nanoparticles in MV3 cells with extended nanoparticle exposure time. The green fluorescence signal in the cells was weak at $1 \mathrm{~h}$ and increased as time progressed. Obvious fluorescence could be seen at $6 \mathrm{~h}$ and $12 \mathrm{~h}$, indicating the uptake of many nanoparticles by the cells, and most of them were co-located with lysosomes. These results showed that the uptake of nanoparticles by MV3 cells was time-dependent under the experimental conditions (igure S2).

\section{Active Targeting Analysis}

Nanoparticles modified with HA can specifically target tumor cells overexpressing CD44, whereas cells with low CD44 expression show less internalization. Fluorescence micrographs showed that green granules were significantly 
A

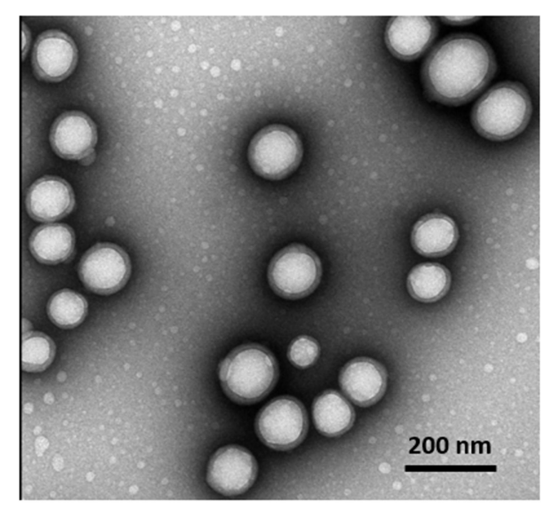

C

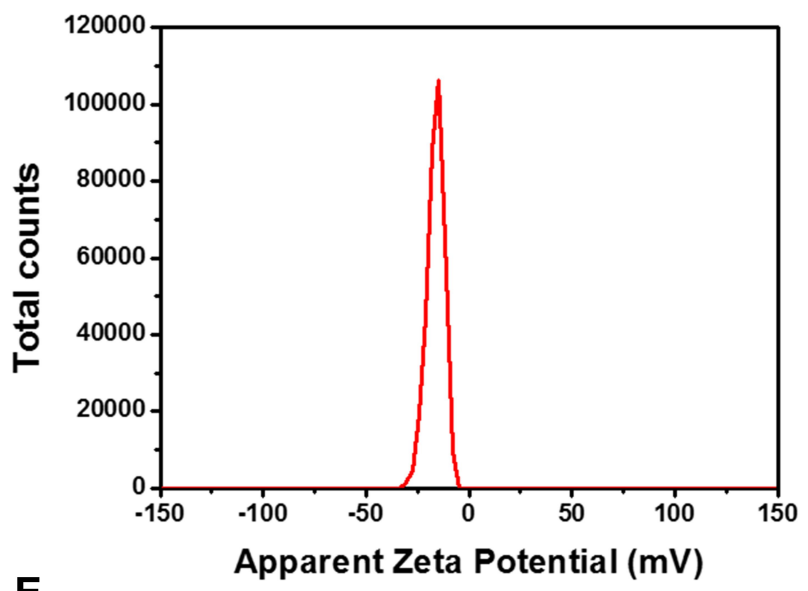

$\mathbf{E}$

Dil

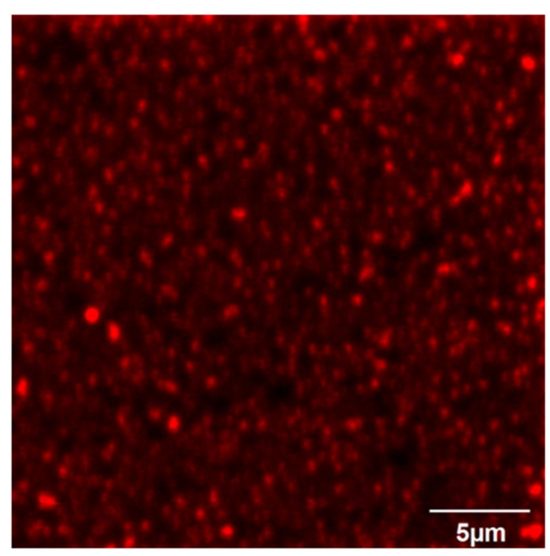

B

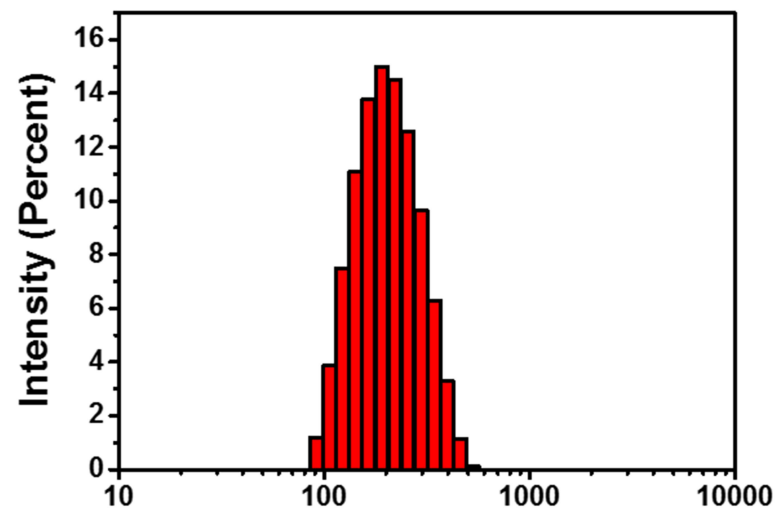

D

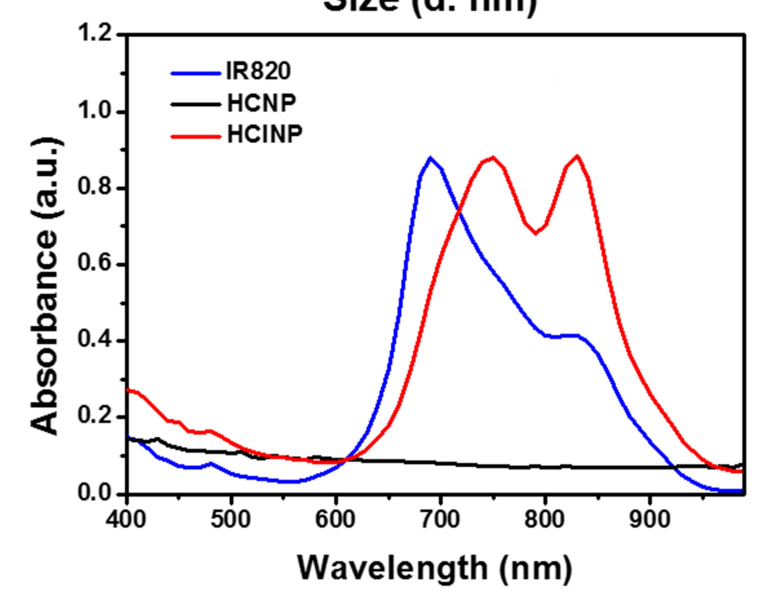

FITC

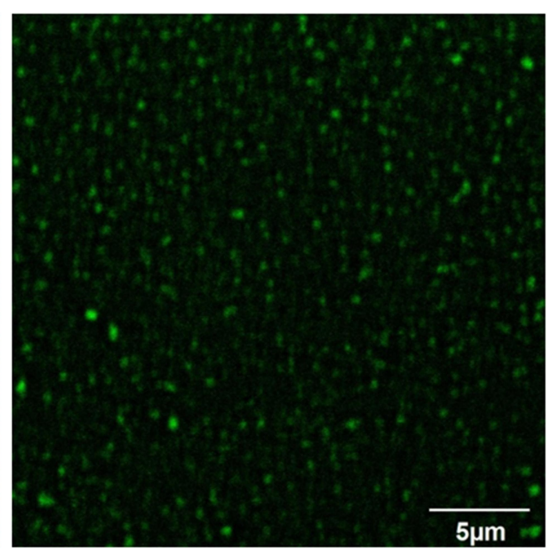

Merge

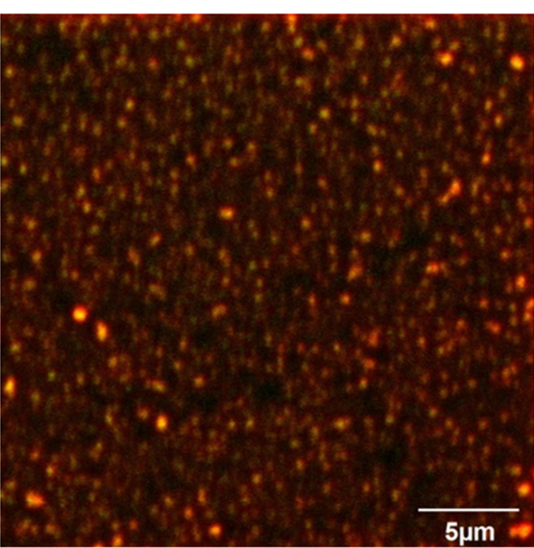

Figure I Identification and characterization of HCINPs. (A) TEM micrographs of HCINPs. (B) Size and (C) zeta potential distribution of HCINPs measured using DLS. (D) Absorption spectra of HCINPs. (E) Detection of HA modification on the surface of the nanoparticle using CLSM.

more abundant in MV3 cells than in HSF cells after $6 \mathrm{~h}$ of exposure (Figure 5A). To further prove that the targeting effect of HCINPs was mediated by HA, free HA and CD44 antibodies were applied to pretreat tumor cells. The results showed that compared with the HCINP group, MV3 cells had less internalization of CINP, and the uptake of HCINP was reduced after pretreatment with HA or CD44 antibodies. These results demonstrated that the HCINPs could play a targeting role through the HACD44 interaction (Figure 5B, $\underline{\mathrm{S} 3}$ ). 
A

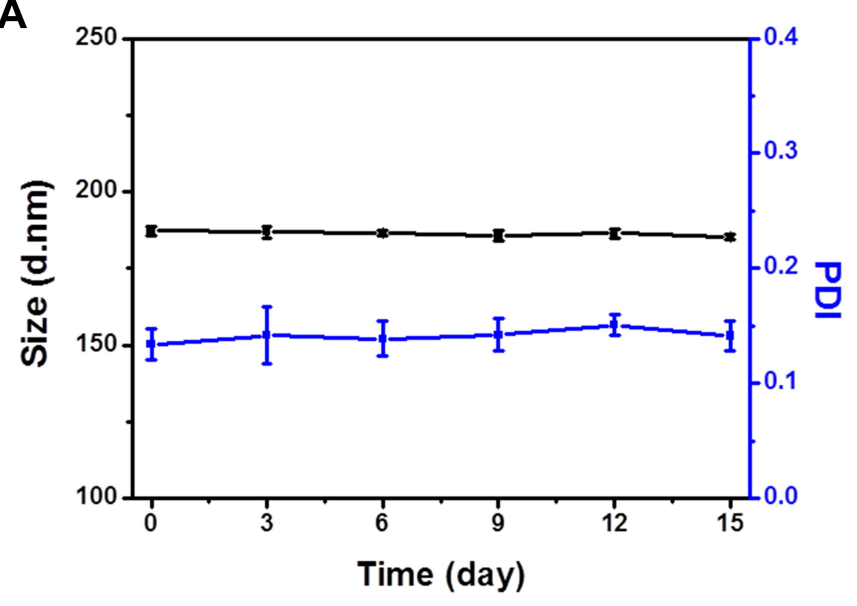

B

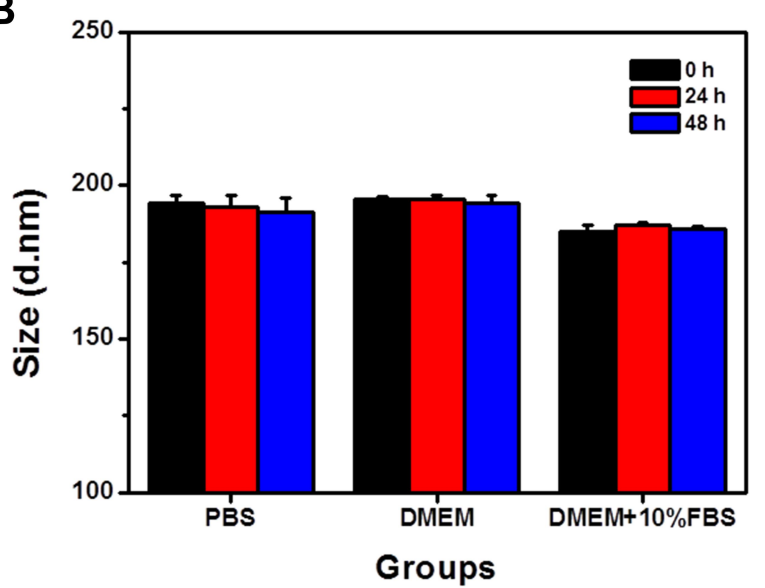

Figure 2 Stability of HCINPs. (A) Hydrodynamic diameter and PDI stability of HCINPs stored in pure water for 15 days. (B) Hydrodynamic diameters of HCINPs in different media measured at 0,24 , and $48 \mathrm{~h}$.

A

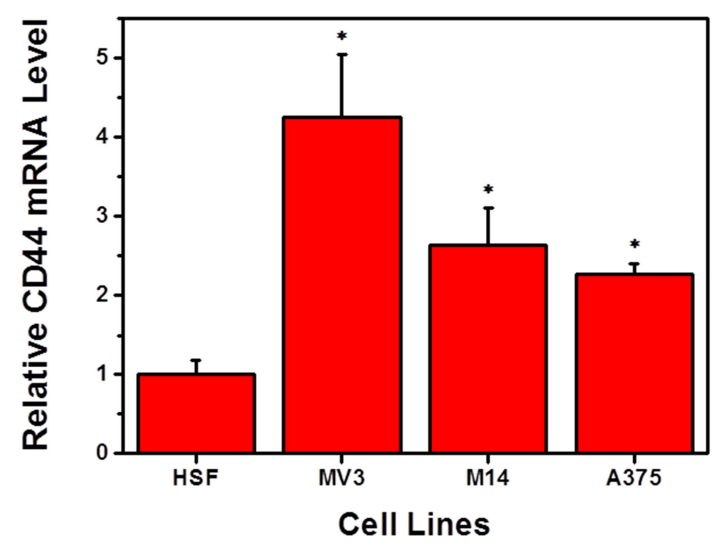

C

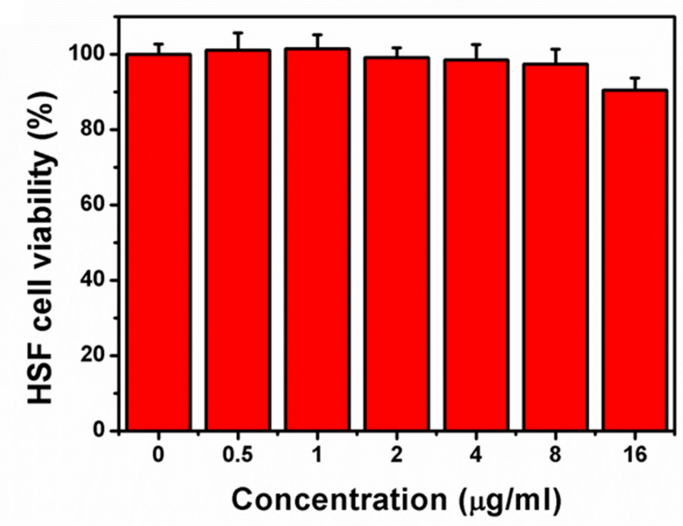

B

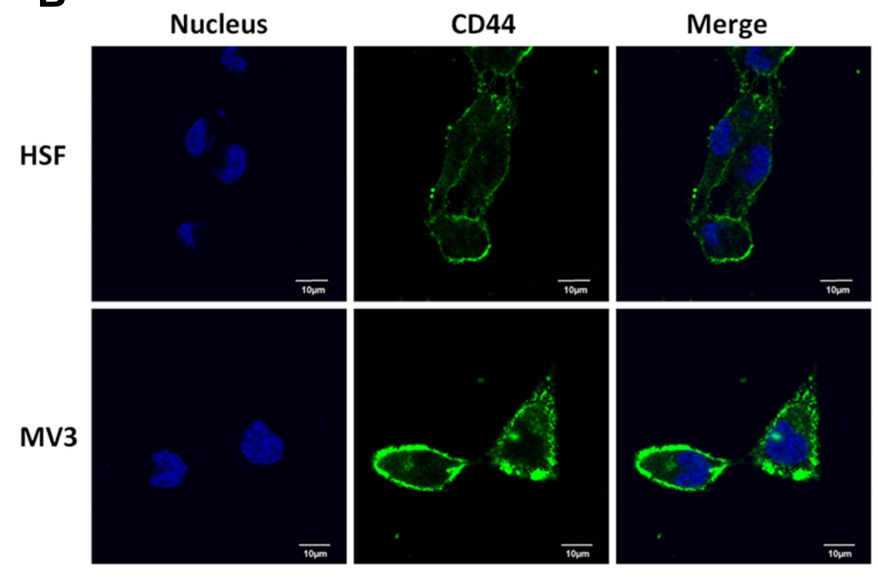

D

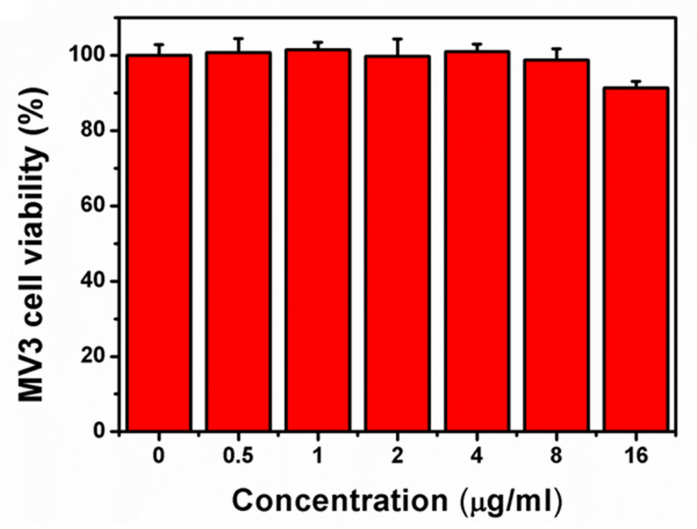

Figure 3 CD44 expression and cytotoxicity measurement. CD44 expression in HSF and melanoma cells measured by (A) qRT-PCR and (B) immunofluorescence assay. Cell viability of (C) HSF and (D) MV3 cells after treatment with different concentrations of HCINPs for 24 h. *P $<0.05$, versus the HSF group. 


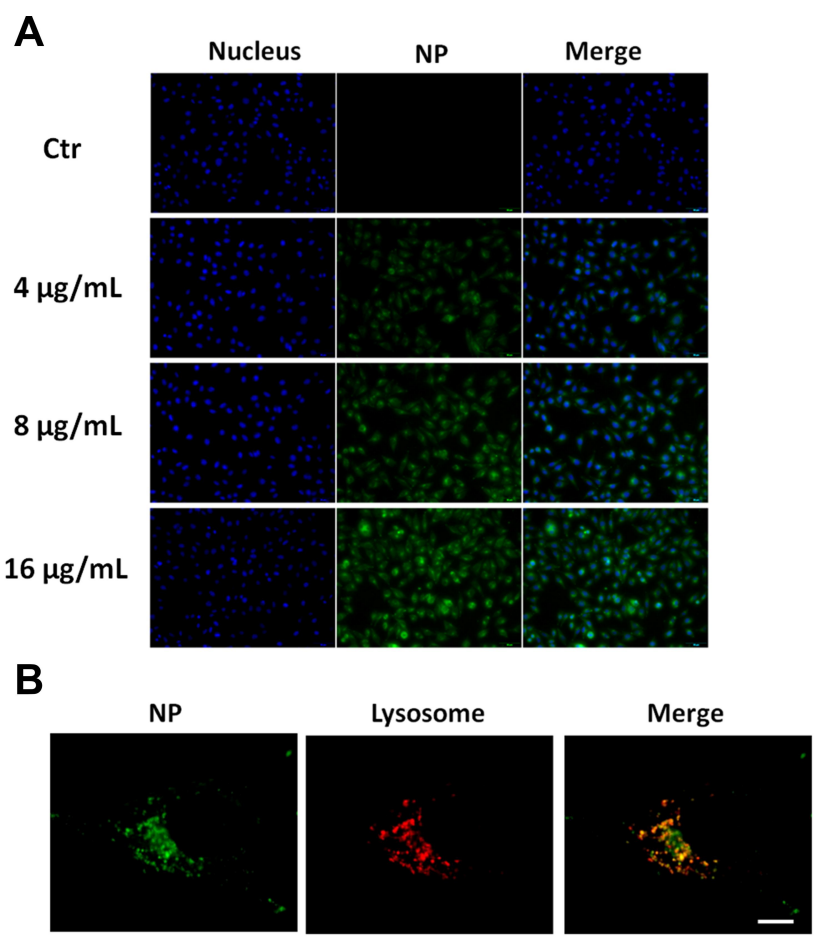

Figure 4 Cellular uptake and intracellular localization of HCINPs in MV3 cells. (A) Dose-dependent cellular uptake of HCINPs by MV3 cells measured using inverted fluorescence microscopy. (B) Colocalization images of HCINPs in MV3 cells by CLSM.

\section{Oxygen Production Capacity Determination}

Oxygen production was determined using ultrasound imaging and optical microscopy. No bubbles were observed in the HCINP group (without $\mathrm{H}_{2} \mathrm{O}_{2}$ ) and the HINPs $+\mathrm{H}_{2} \mathrm{O}_{2}$ group. However, in HCINPs $+\mathrm{H}_{2} \mathrm{O}_{2}$ group, many bubbles were generated, indicating that HCINPs could catalyze $\mathrm{H}_{2} \mathrm{O}_{2}$ to produce oxygen (Figure $6 \mathrm{~A}$ ).

We further studied the ability of HCINPs to produce oxygen in tumor cells. $\left[\mathrm{Ru}(\mathrm{dpp})_{3}\right] \mathrm{Cl}_{2}$ is a dissolved oxygen indicator whose fluorescence can be quenched by oxygen, resulting in decreased red fluorescence intensity. ${ }^{24} \mathrm{MV} 3$ cells were treated with different concentrations of HCINPs for $12 \mathrm{~h}$ and then observed using inverted fluorescence microscopy. The cells without HCINP exposure showed bright red fluorescence, while the fluorescence intensity was significantly weakened in HCINP-treated cells. The average fluorescence intensity decreased as the concentration of the nanoparticles increased (Figure 6B). These results suggested that the CAT activity in the HCINPs could catalyze oxygen production from $\mathrm{H}_{2} \mathrm{O}_{2}$ in tumor cells.

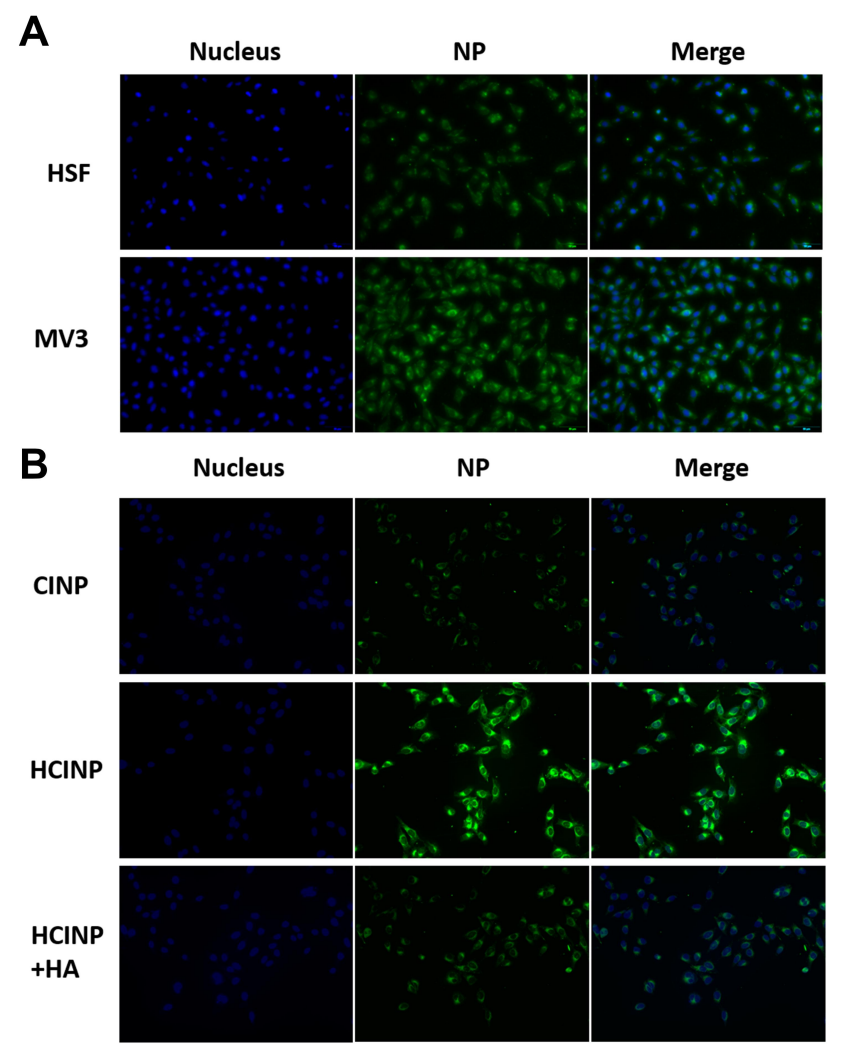

Figure 5 Targeting effect of HCINPs (NP). (A) Uptake of HCINPs by HSF and MV3 cells measured by inverted fluorescence microscopy. (B) Uptake of CINPs, HCINPs, and HCINPs by MV3 cells pretreated with HA (200x).

\section{HCINP Formulation-Mediated Enhanced PDT in vitro}

A calcein-AM/PI double staining assay was carried out to detect the PDT effect of HCINPs. The experimental results showed that there was no significant cell death in the $\mathrm{Ctr}$ group, NIR group, and HCINP group, and the cell morphology was normal, indicating that the nanoparticles had good biocompatibility, which was consistent with the CCK-8 experimental results. IR820 caused partial cell death after NIR laser irradiation, but most cells remained alive. The amount of cell death in the CINP+NIR group and HINP+NIR group increased further, but there were still some residual cells, and the morphology of the residual cells changed. In the HCINP+NIR group, almost all cells in the irradiated area died, showing a strong tumor cell killing effect (Figure 7).

\section{HCINP Formulation-Mediated Enhanced PDT in vivo}

Before analyzing the antitumor treatment, we first studied the targeting of HCINPs in vivo. CINPs and HCINPs were 
A
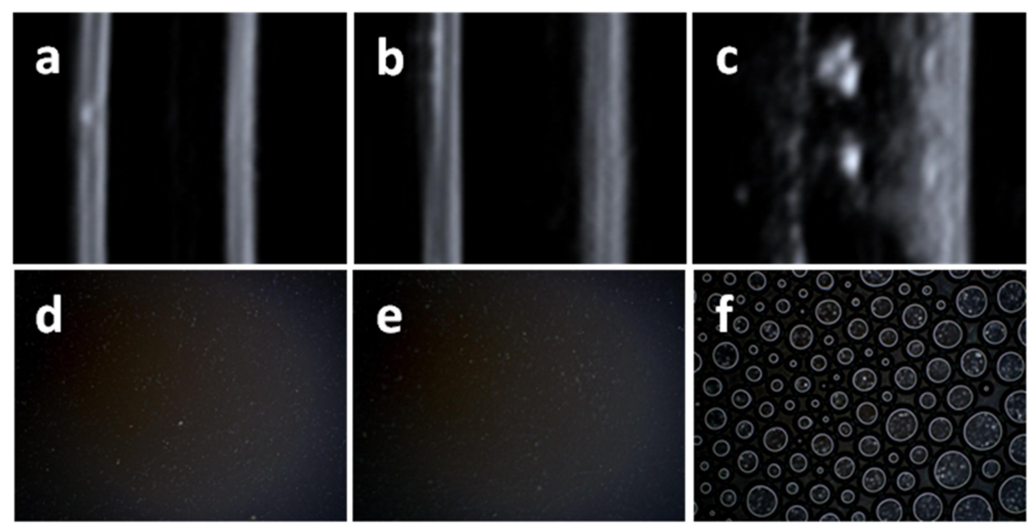

B

Ctr

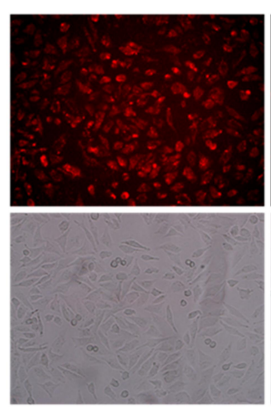

NP-4

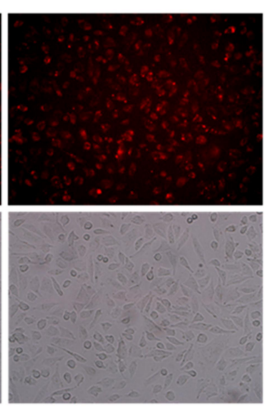

NP-8

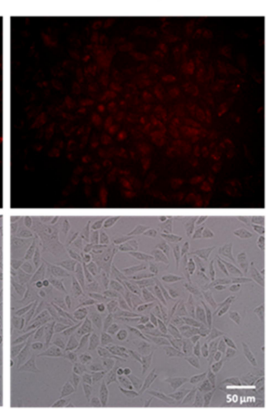

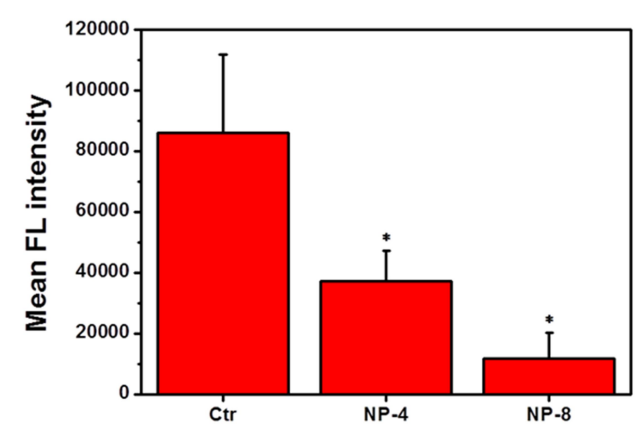

Figure 6 Oxygen production determination. (A) Ultrasound imaging (a: $\mathrm{HINPs}+\mathrm{H}_{2} \mathrm{O}_{2}$, b: $\mathrm{HCINPs}$, and c: $\mathrm{HCINPs}_{2}+\mathrm{H}_{2} \mathrm{O}_{2}$ ) and optical microscopy (d: $\mathrm{HINPs}+\mathrm{H}_{2} \mathrm{O}_{2}$, e: $\mathrm{HCINPs}$, and $\mathrm{f}: \mathrm{HCINPs}+\mathrm{H}_{2} \mathrm{O}_{2}$ ) indicating the oxygen generation of the $\mathrm{HCINPs}$ incubated with $\mathrm{H}_{2} \mathrm{O}_{2}$. (B) Intracellular generation of oxygen after $\mathrm{HCINPs}$ (NP) exposure; $* \mathrm{P}<0.05$, versus the control ( $\mathrm{Ctr})$ group.

injected into the tail vein of the tumor-bearing mice, and fluorescence imaging was achieved using an in vivo Imaging System. As shown in Figure 8A, after $24 \mathrm{~h}$ of drug administration, HCINPs could largely accumulate in tumor tissues, with a small amount in the kidney, while no obvious fluorescence was observed in other tissues and organs. However, CINPs could enter tumor tissues in a small amount, and the fluorescent signal was also detected in liver and kidney. Therefore, HCINPs can specifically accumulate in the tumor, and cause insignificant effects on other tissues.

The HIF- $1 \alpha$ content in tumor tissue is regulated by the oxygen concentration; thus HIF-1 $\alpha$ levels can reflect hypoxia of the tumor microenvironment. Immunohistochemistry showed that after nanoparticles administration, the HIF- $1 \alpha$ content was higher in the Ctr group (1522) and HINP group (1503), with no significant difference between them, while HIF-1 $\alpha$ levels in the HCINP group (1092) were significantly reduced (Figure 8B). CAIX, as an important target molecule of HIF-1 $\alpha$, is another reliable hypoxia marker. Immunofluorescence results revealed that CAIX was highly expressed in tumor tissues in the Ctr group and HINP group, while its expression was decreased in HCINP-treated group, indicating that hypoxia in tumor tissues was alleviated, consistent with the detection results of HIF-1 $\alpha$ (Figure S4). Thus, injected HCINPs could target tumor tissues, catalyze the production and release of oxygen by $\mathrm{H}_{2} \mathrm{O}_{2}$, improve the oxygen concentration, and reverse the hypoxic state of the tumor microenvironment.

PDT efficacy was assessed by monitoring tumor volume in different groups of mice. The tumor growth curve (Figure $8 \mathrm{C}$ ) showed that the tumor volume in the $\mathrm{Ctr}$ and the HCINP groups increased rapidly. The tumor growth rate in the NIR group slowed slightly, but still showed rapid growth. Tumor growth was inhibited in the IR820+NIR group, indicating that free IR820 could kill tumor cells under NIR irradiation; however, the tumors continued to grow because of the limited PDT effect. The tumor growth rates in the CINPs+NIR and HINPs+NIR groups were significantly slower than those in the IR820 

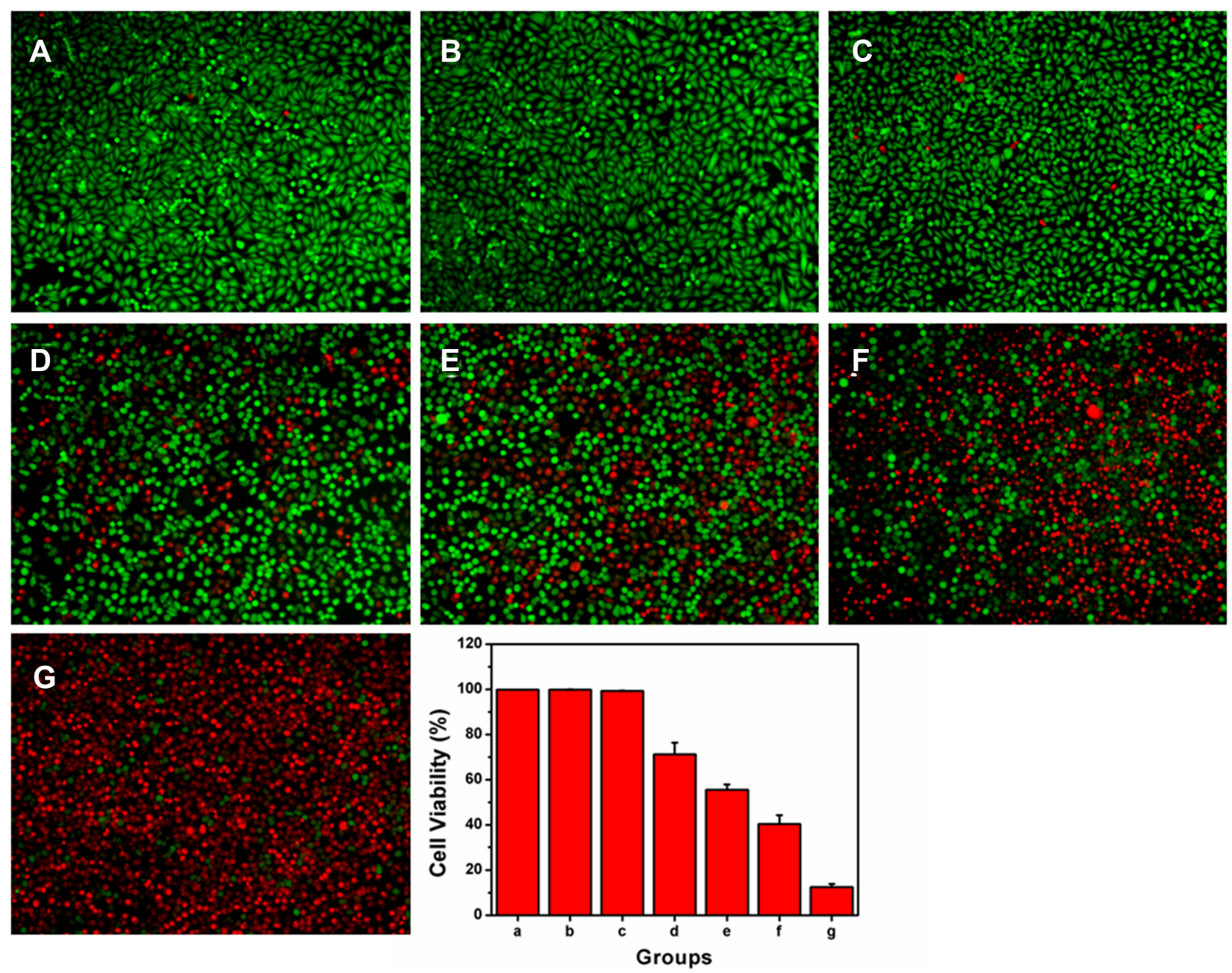

Figure 7 Enhanced PDT mediated by HCINPs was studied using the live-dead method in vitro. (A) Ctr group, cells without nanoparticles exposure and NIR irradiation; (B) NIR group, cells with NIR irradiation, but without nanoparticles exposure; (C) HCINP group, cells with HCINPs exposure, but without NIR irradiation; (D) IR820+NIR group, cells with IR820 exposure and NIR irradiation; (E) CINP+NIR group, cells with CINPs exposure and NIR irradiation; (F) HINP+NIR group, cells with HINPs exposure and NIR irradiation; (G) HCINP+NIR group, cells with HCINPs exposure and NIR irradiation.

+NIR group. Tumors in the HCINPs+NIR group almost completely disappeared by the 14th day, revealing an enhanced PDT effect to effectively kill melanoma cells.

To assess the therapeutic safety of HCINPs+NIR in vivo, the body weights of mice during treatment and histopathological examination of major organs (heart, liver, spleen, lung, and kidney) were performed. There was no significant decrease in mouse body weight in all groups during treatment (Figure 8D). Hematoxylin and eosin (HE) staining revealed no significant pathological changes in the organs after 14 days of HCINPs+NIR treatment compared with that in the normal group (Figure 8E). These results suggested that HCINP nanoparticle-mediated PDT therapy has good biosafety.

\section{Discussion}

The unique physical and chemical properties, and biological functions of nanomedicine have attracted increased attention, becoming a research hotspot in cancer treatment in recent years. Numerous nano-drugs, such as Doxil ${ }^{\circledR}$, Marqibo $^{\circledR}$, and Abraxane ${ }^{\circledR}$ have been developed and received US FDA approval for clinical use, with more under pre-clinical and clinical trials. ${ }^{25,26}$ Nanomaterials remain the top priority in nanotechnology, with unique functions such as conditional responsiveness (temperature, $\mathrm{pH}$, and light), imaging properties, enzyme catalytic activity, and antigenicity (adjuvant) being developed in nanomedicine in the past decade. ${ }^{27-29}$ PLGA is a high molecular weight polymer comprising different ratios of 
A
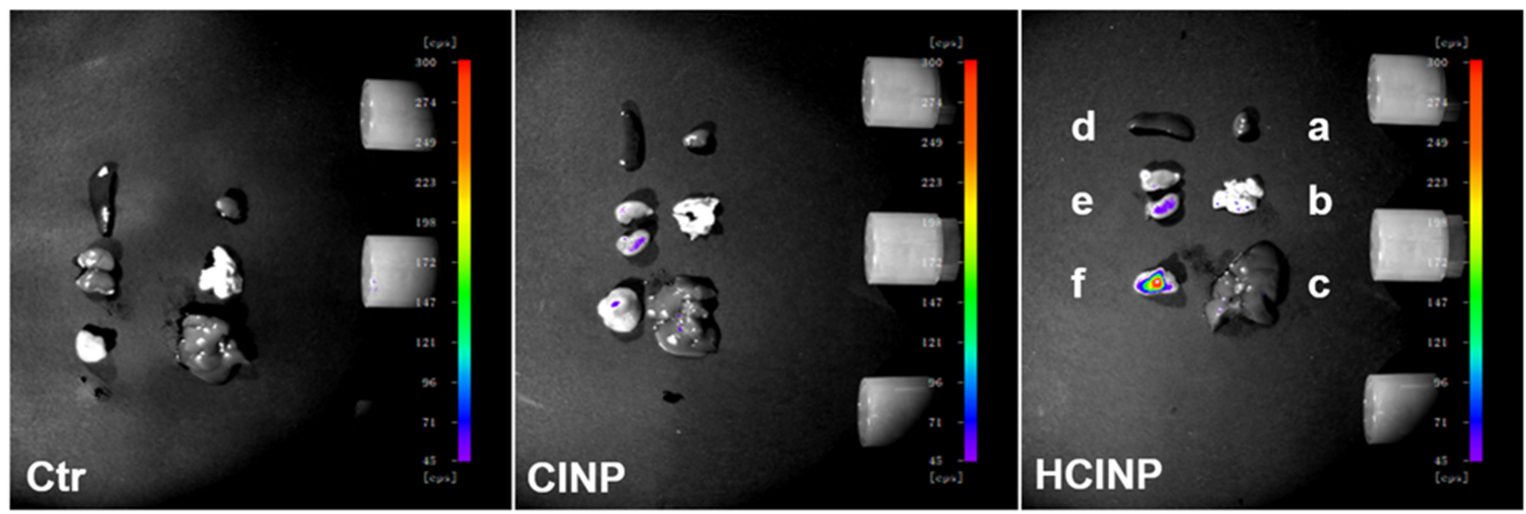

B
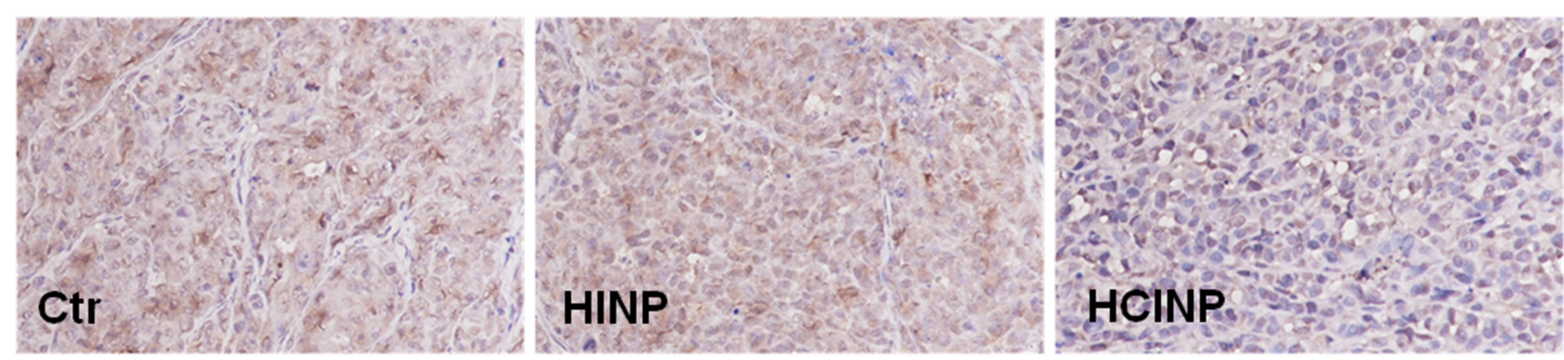

C

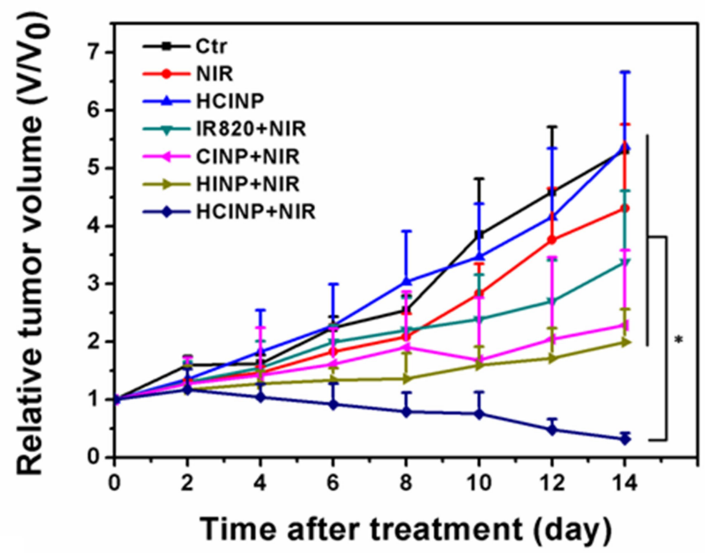

D

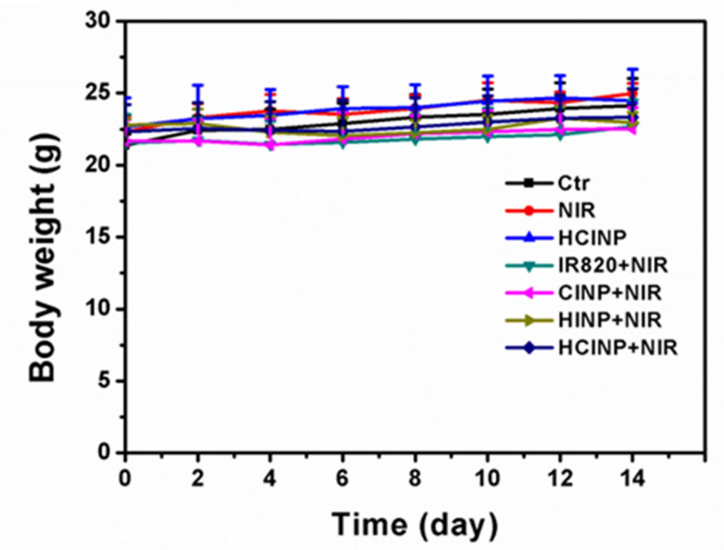

E

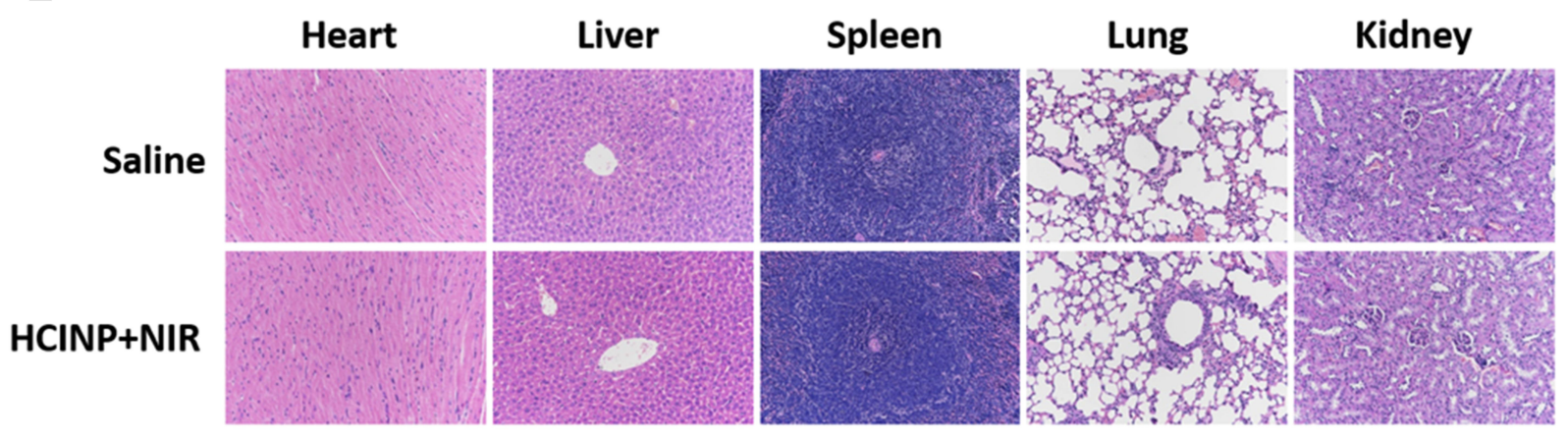

Figure 8 Enhanced anti-tumor effect of HCINPs. (A) Measurement of the in vivo targeting effect of HCINPs (a: heart, b: lung, c: liver, d: spleen, e: kidney, f: tumor). (B) Expression of HIF-I $\alpha$ in tumor tissues (200x). The mean positive area of the Ctr group, HINP group, and HCINP group were I522, I503, and I092, respectively. (C) Relative tumor-volume curves of different groups of MV3 tumor-bearing mice. ${ }^{*} \mathrm{P}<0.05$, versus the $\mathrm{HCINP}$ group. (D) Body weights of mice measured during the 14 observation days in different groups. (E) HE-staining images of major organs collected from the saline (Normal) and HCINPs with NIR irradiation groups (200x). 
lactic acid and glycolic acid. PLGA has many advantages compared with other nanomaterials, including good biocompatibility, easy film formation, excellent plasticity, and biodegradability. PLGA based-nanoparticles also show superior stability; high mechanical strength, and good encapsulation of hydrophilic and hydrophobic drugs, proteins, and DNA. ${ }^{30,31}$ Therefore, PLGA is frequently selected to prepare drug-loaded nanoparticles. In this study, double emulsion solvent evaporation was selected to encapsulate the hydrophilic IR820 and CAT to prepare the PLGA nanoparticles. TEM images showed that the nanoparticles were monodisperse and spherical, with an average size of $121.8 \mathrm{~nm}$. DLS measurement showed that the average hydrodynamic diameter of the HCINPs was $187.4 \mathrm{~nm}$, which was larger than the TEM finding because of the differences in their measurement mechanisms and the existence of the hydrated layer on the surface of the nanoparticles. ${ }^{32,33}$ The PDI value was 0.125 , suggesting a homogeneous size distribution and good monodispersity. Oxygen generation experiments showed that incubation of HCINPs with $\mathrm{H}_{2} \mathrm{O}_{2}$ resulted in the formation of a large number of bubbles, indicating the good enzyme activity of CAT in HCINPs.

Lack of targeting to tumor cells restricts the application and development of traditional anti-tumor drugs, including chemotherapy agents and photosensitizers, and is one of the root causes for their low efficacy and various side effects. Nanomedicine has a passive targeting capability, termed the enhanced permeability and retention (EPR) effect, resulting from abnormal tumor vascular integrity and lymphatic drainage dysfunction. ${ }^{34}$ In addition, targeting molecules can be modified on nanocarriers to selectively bind to overexpressed receptors on the tumor cells, such as the folate receptor, transferrin receptor, and epidermal growth factor receptor, to mediate cellular drug uptake. ${ }^{35}$ CD44 is a transmembrane glycoprotein involved in the adhesion between tumor cells and host cells or the extracellular matrix, which promotes tumor cell invasion and metastasis. ${ }^{36} \mathrm{CD} 44$ is highly expressed in a variety of tumor cells including breast cancer, liver cancer, lung cancer, and prostate cancer. ${ }^{37-40}$ Therefore, CD44 is a potential target for tumor-targeted therapy. As a ligand of the CD44 receptor, HA is an acid mucopolysaccharide comprising D-N-acetylglucosamine and D-glucuronic acid, which can bind to CD44 and induce receptormediated incorporation. In the present study, the surface of the PLGA nanoparticle was modified with HA to allow active targeting of melanoma cells. The TEM result showed that the morphology of the HCINP nanoparticles was consist with a drug-filled core and a shell formed by PLGA and HA. To further verify successful HA modification, dual-fluorescence labeling was used to observe the relative position of HA and PLGA nanoparticles. CLSM images showed co-localization of HA with the PLGA nanoparticles, demonstrating successful HA modification. After HCINP exposure, significant uptake of nanoparticles by MV3 cells was observed, and cellular internalization increased in a dose-dependent and time-dependent manner. At the same nanoparticle concentration, the uptake by CD44-positive MV3 cells was greater than that of HSF cells (low CD44 expression). Moreover, pretreatment of tumor cells with free HA or CD44 antibodies resulted in a decrease in nanoparticle uptake. These results indicated that the nanoparticles could selectively target tumor cells with high CD44 expression. Moreover, DLS showed that the nanoparticles had an average hydrodynamic diameter of $187.4 \mathrm{~nm}$; therefore, they could enter the tumor site through the endothelial space of the tumor blood vessels (diameter approximately $380-780 \mathrm{~nm}$ ). ${ }^{41}$ Therefore, the as synthesized drug delivery nanosystem could accurately deliver drugs to tumor cells via passive and active targeting effects. The in vivo imaging experiment further support this conclusion.

Stability is an important property of nanomedicines, and it the basis for long-term preservation and clinical application. Nanoparticle stability is related to their charge, surfactants, surface modifications, and solution properties. ${ }^{42,43}$ The DLS results showed that the particle size and PDI of HCINP did not change significantly over 15 days, indicating that the nanoparticles maintained their monodispersed state in aqueous solution without agglomeration or decomposition, probably because of the repulsion effect of the strong negative charge $(-16.3 \mathrm{mV})$. Nanoparticles will interact with salts and biomolecules in the cell culture environment or in organisms, which might affect their subsequent cellular uptake. ${ }^{44}$ Therefore, we studied the stability of HCINPs in PBS, DMEM, and DMEM $+10 \%$ FBS. The particle size in PBS and DMEM increased slightly (but was still less than $200 \mathrm{~nm}$ ), which might reflect the presence of many ions in these solutions, which would affect the charge of the nanoparticles. The hydrodynamic diameter of the HCINPs in DMEM $+10 \%$ FBS was unchanged, probably because of the negatively charged proteins in the solution. Furthermore, the particle size in all three solutions did not change significantly upon 
further incubation. Thus, the HCINPs showed good stability in aqueous solution and physiological environments.

The hypoxic tumor microenvironment limits the efficacy of PDT, thus reversing the hypoxic state, which could enhance the tumor-killing effect. In addition, to deliver oxygen to the tumor site directly, the high $\mathrm{H}_{2} \mathrm{O}_{2}$ concentration in tumor tissue could be used to generate oxygen to regulate hypoxia. Ma et al prepared $\mathrm{MnO}_{2}$ nanoparticles that could react with $\mathrm{H}_{2} \mathrm{O}_{2}$ to produce oxygen, resulting in increased singlet oxygen levels for PDT treatment. ${ }^{44}$ Yang et al co-delivered Prussian blue with catalase-like activity and a photosensitizer to the tumor to achieve an oxygen self-enrichment effect. ${ }^{13}$ Although these strategies displayed satisfactory results in in vitro and in vivo experiments, problems such as the metabolism of inorganic materials in the body, potential toxicity, and reaction and catalytic activity in tumor cells cannot be ignored. CAT, an inherent protease in the human body, can be used to catalyze the production of oxygen from $\mathrm{H}_{2} \mathrm{O}_{2}$. Chen et al loaded CAT and a photosensitizer into PLGA nanoparticles and further modified them with cyclo-(Arg-Gly-Asp -D-Phe-Lys) (c(RGDfK)) to achieve targeted drug-delivery to tumor. The results showed that the nanoparticles catalyzed $\mathrm{H}_{2} \mathrm{O}_{2}$ in the tumor cells to generate oxygen, resulting in increased singlet oxygen levels to kill tumor cells. ${ }^{45}$ However, the photosensitizer used in their study was methylene blue, and the light wavelength was $635 \mathrm{~nm}$, and thus represented the limitations of conventional photosensitizers. In the present study, we encapsulated CAT and the near-infrared photosensitizer IR820 into the PLGA nanoparticles, which were surface-coated with HA. Ultrasound imaging and optical microscopy showed that many oxygen bubbles were generated after co-incubation of HCINPs with $\mathrm{H}_{2} \mathrm{O}_{2}$. Intracellular oxygen production, assessed via the fluorescence intensity of $\left[\mathrm{Ru}(\mathrm{dpp})_{3}\right] \mathrm{Cl}_{2}$, decreased significantly in tumor cells treated with HCINP compared with that in the control cells, in an HCINP concentration-dependent manner, indicating that HCINP could catalyze $\mathrm{H}_{2} \mathrm{O}_{2}$ in tumor cells to produce oxygen.

HIF-1 is a transcriptionally active nuclear protein comprising HIF- $1 \alpha$ and HIF-1 $\beta$ subunits. ${ }^{46}$ Hypoxia regulates the tumor HIF-1 $\alpha$ content. Under normal oxygen conditions, HIF- $1 \alpha$ is rapidly degraded via the intracellular oxygendependent ubiquitin protease degradation pathway, while under hypoxic condition, the degradation pathway is blocked and HIF- $1 \alpha$ remains stable. ${ }^{47,48}$ Therefore, the HIF- $1 \alpha$ levels in tumor tissues reflect hypoxia of the tumor microenvironment. Immunohistochemistry showed that after nanoparticle administration, the HIF-1 $\alpha$ level was higher in the $\mathrm{Ctr}$ and HINP groups, while its level was reduced significantly in the
HCINP group, suggesting that HCINPs could relieve hypoxia, resulting in HIF-1 $\alpha$ degradation in tumor tissues.

In recent years, the application of nanoparticles carrying NIR photosensitizers for PDT has developed rapidly; ${ }^{49,50}$ however, the hypoxic environment of a solid tumor will undoubtedly impede the efficacy of PDT treatment. Increased oxygen in tumor tissue provides abundant substrates to produce more singlet oxygen, thereby enhancing PDT's anti-tumor effect. The tumor volume in the Ctr and HCINP mouse groups increased rapidly, indicating that treatment with HCINPs alone did not affect tumor growth. The tumor growth rate in the NIR group slowed slightly, which might have been caused by laser stimulation; however, tumor growth remained rapid. In the IR820+NIR group, tumor growth was inhibited, indicating that free IR820 could induce PDT to partially inhibit tumor growth under NIR laser irradiation. However, the lack of targeting limited the uptake of free IR 820 by tumor cells, thus the PDT effect was poor. CINP could deliver IR820 to the tumor via passive targeting, and the presence of CAT could increase the local oxygen concentration, thereby increasing the yield of singlet oxygen, generating a stronger anti-tumor effect than that of free IR820. Unfortunately, it could not kill all the tumor cells, and the tumors appeared to regrow in the later stage. The HINPs, via active and passive targeting, could increase the concentration of drugs in tumors, showing a strong anti-tumor effect. However, because the local hypoxia state in tumors was not reversed, and the PDT treatment aggravated the hypoxia, tumor inhibition was unsatisfactory. After HCINPs+NIR treatment, the tumors almost completely disappeared on the 14th day, which could be attributed to the effective drug accumulation in the tumor through active and passive targeting, and the self-sufficient generation singlet oxygen, which effectively killed the tumor cells. Compared with the work of $\mathrm{Li}$ et al $\left(2 \mathrm{mg} / \mathrm{kg}, 2.5 \mathrm{~W} / \mathrm{cm}^{2}\right.$ for $\left.10 \mathrm{~min}\right),{ }^{11}$ the nanoparticles we constructed achieved similar therapeutic effects using a lower dose of the drug and shorter exposure times $\left(1 \mathrm{mg} / \mathrm{kg}, 4 \mathrm{~W} / \mathrm{cm}^{2}\right.$ for $\left.5 \mathrm{~min}\right)$. Weight monitoring and histopathological examinations results showed that HCINPs+NIR treatment had insignificant systemic side effects in the mice, suggesting that it is a safe and effective anti-tumor strategy.

\section{Conclusions}

We developed a CD44-targeting, oxygen self-sufficient nanocomposite, HCINP, which simultaneously encapsulated CAT and the near-infrared photosensitizer IR820. The HCINPs 
were monodisperse spheres, stable in various solutions, and could catalyze $\mathrm{H}_{2} \mathrm{O}_{2}$ to generate oxygen. Anti-tumor experiments in vitro and in vivo confirmed that the drug delivery system could target tumor cells, generate oxygen, relieve local hypoxia, and exert an enhanced PDT effect under NIR laser irradiation. Therefore, the developed HCINPs could be applied to relieve the hypoxic state in the tumor microenvironment and improve the efficacy of PDT, representing a basis to exploring innovative strategies to treat melanoma.

\section{Acknowledgments}

This research was supported by the National Natural Science Foundation of China (Nos. 81572976, 81872493, 81803151), the China Postdoctoral Science Foundation (Nos.2016M590505, 2017T100407), the Jiangsu Provincial Medical Talent Foundation, the 'Six Talent Peaks' Project of Jiangsu Province (Nos.WSW-074, WSN-254), and the Science and Technology Project of Huai'an city (No. HAB201812).

\section{Disclosure}

The authors declare no conflict of interest.

\section{References}

1. Han K, Wang SB, Lei Q, et al. Ratiometric biosensor for aggregation-induced emission-guided precise photodynamic therapy. ACS Nano. 2015;9:10268-10277.

2. van Straten D, Mashayekhi V, de Bruijn HS, et al. Oncologic photodynamic therapy: basic principles, current clinical status and future directions. Cancers (Basel). 2017;9.

3. Cao H, Wang L, Yang Y, et al. An assembled nanocomplex for improving both therapeutic efficiency and treatment depth in photodynamic therapy. Angew Chem Int Ed Engl. 2018;57:7759-7763.

4. Liang H, Zhou Z, Luo R, et al. Tumor-specific activated photodynamic therapy with an oxidation-regulated strategy for enhancing anti-tumor efficacy. Theranostics. 2018;8:5059-5071.

5. Zhang J, Jiang C, Figueiro Longo JP, et al. An updated overview on the development of new photosensitizers for anticancer photodynamic therapy. Acta Pharm Sin B. 2018;8:137-146.

6. Conceicao DS, Ferreira DP, Ferreira LF. Photochemistry and cytotoxicity evaluation of heptamethinecyanine near infrared (NIR) dyes. Int J Mol Sci. 2013;14:18557-18571.

7. Saneja A, Kumar R, Arora D, et al. recent advances in near-infrared light-responsive nanocarriers for cancer therapy. Drug Discov Today. 2018;23:1115-1125.

8. Lei T, Fernandez-Fernandez A, Manchanda R, et al. Near-infrared dye loaded polymeric nanoparticles for cancer imaging and therapy and cellular response after laser-induced heating. Beilstein J Nanotechnol. 2014;5:313-322.

9. Fernandez-Fernandez A, Manchanda R, Lei T, et al. Comparative study of the optical and heat generation properties of IR820 and indocyanine green. Mol Imaging. 2012;11:99-113.

10. Liao J, Wei X, Ran B, et al. Polymer Hybrid magnetic nanocapsules encapsulating IR820 and PTX for external magnetic field-guided tumor targeting and multifunctional theranostics. Nanoscale. 2017;9:2479-2491.
11. Li W, Peng J, Tan L, et al. Mild photothermal therapy/photodynamic therapy/chemotherapy of breast cancer by Lyp-1 modified docetaxel/ IR820 co-loaded micelles. Biomaterials. 2016;106:119-133.

12. Zhou H, Hou X, Liu Y, et al. superstable magnetic nanoparticles in conjugation with near-infrared dye as a multimodal theranostic platform. ACS Appl Mater Interfaces. 2016;8:4424-4433.

13. Yang ZL, Tian W, Wang Q, et al. oxygen-evolving mesoporous organosilica coated prussian blue nanoplatform for highly efficient photodynamic therapy of tumors. Adv Sci (Weinh). 2018;5:1700847.

14. Cheng Y, Cheng H, Jiang C, et al. Perfluorocarbon nanoparticles enhance reactive oxygen levels and tumour growth inhibition in photodynamic therapy. Nat Commun. 2015;6:8785.

15. Guo X, Qu J, Zhu C, et al. Synchronous delivery of oxygen and photosensitizer for alleviation of hypoxia tumor microenvironment and dramatically enhanced photodynamic therapy. Drug Deliv. 2018;25:585-599.

16. Kim J, Cho HR, Jeon H, et al. Continuous O2-evolving $\mathrm{MnFe} 2 \mathrm{O} 4$ nanoparticle-anchored mesoporous silica nanoparticles for efficient photodynamic therapy in hypoxic cancer. $J$ Am Chem Soc. 2017;139:10992-10995.

17. Hu D, Chen Z, Sheng Z, et al. A catalase-loaded hierarchical zeolite as an implantable nanocapsule for ultrasound-guided oxygen self-sufficient photodynamic therapy against pancreatic cancer. Nanoscale. 2018;10:17283-17292.

18. Bowerman CJ, Byrne JD, Chu KS, et al. Docetaxel-loaded PLGA nanoparticles improve efficacy in taxane-resistant triple-negative breast cancer. Nano Lett. 2017;17:242-248.

19. Chen Q, Xu L, Liang C, et al. Photothermal therapy with immune-adjuvant nanoparticles together with checkpoint blockade for effective cancer immunotherapy. Nat Commun. 2016;7:13193.

20. Byeon Y, Lee JW, Choi WS, et al. CD44-targeting PLGA nanoparticles incorporating paclitaxel and FAK siRNA overcome chemoresistance in epithelial ovarian cancer. Cancer Res. 2018; 78:6247-6256.

21. Nel AE, Mädler L, Velegol D, et al. Understanding biophysicochemical interactions at the nano-bio interface. Nat Mater. 2009;8:543-557.

22. Dietrich A, Tanczos E, Vanscheidt W, et al. High CD44 surface expression on primary tumours of malignant melanoma correlates with increased metastatic risk and reduced survival. Eur $J$ Cancer. 1997;33:926-930.

23. Yu M, Jambhrunkar S, Thorn P, et al. Hyaluronic acid modified mesoporous silica nanoparticles for targeted drug delivery to CD44-overexpressing cancer cells. Nanoscale. 2013;5:178-183.

24. Yang Z, Wen J, Wang Q, et al. Sensitive, real-time and in-vivo oxygen monitoring for photodynamic therapy by multifunctional mesoporous nanosensors. ACS Appl Mater Interfaces. 2019; 11:187-194

25. Dawidczyk CM, Kim C, Park JH, et al. State-of-the-art in design rules for drug delivery platforms: lessons learned from FDA-approved nanomedicines. $J$ Control Release. 2014; 187:133-144.

26. Bobo D, Robinson KJ, Islam J, et al. Nanoparticle-based medicines: a review of FDA-approved materials and clinical trials to date. Pharm Res. 2016;33:2373-2387.

27. Zhang ZQ, Song SC. Thermosensitive/superparamagnetic iron oxide nanoparticle- loaded nanocapsule hydrogels for multiple cancer hyperthermia. Biomaterials. 2016;106:13-23.

28. Dong Z, Feng L, Zhu W, et al. CaCO3 nanoparticles as an ultra-sensitive tumor-Ph-responsive nanoplatform enabling real-time drug release monitoring and cancer combination therapy. Biomaterials. 2016;110:60-70.

29. Wang $\mathrm{C}, \mathrm{Xu} \mathrm{L}$, Liang $\mathrm{C}$, et al. Immunological responses triggered by photothermal therapy with carbon nanotubes in combination with anti-CTLA-4 therapy to inhibit cancer metastasis. Adv Mater. 2014;26:8154-8162. 
30. Kapoor DN, Bhatia A, Kaur R, et al. PLGA: a unique polymer for drug delivery. Ther Deliv. 2015;6:41-58.

31. Xu Y, Kim CS, Saylor DM, et al. Polymer degradation and drug delivery in PLGA-based drug-polymer applications: a review of experiments and theories. J Biomed Mater Res B Appl Biomater. 2017;105:1692-1716.

32. Gui R, Wan A, Liu X, et al. Water-soluble multidentate polymers compactly coating $\mathrm{Ag} 2 \mathrm{~S}$ quantum dots with minimized hydrodynamic size and bright emission tunable from red to second near-infrared region. Nanoscale. 2014;6:5467-5473.

33. Ahamed M, Posgai R, Gorey TJ, et al. Silver nanoparticles induced heat shock protein 70, oxidative stress and apoptosis in drosophila melanogaster. Toxicol Appl Pharmacol. 2010;242:263-269.

34. Ngoune R, Peters A, von Elverfeldt D, et al. Accumulating nanoparticles by EPR: a route of no return. $J$ Control Release. 2016;238:58-70.

35. Hou XY, Jiang G, Yang CS, et al. Application of nanotechnology in the diagnosis and therapy of hepatocellular carcinoma. Recent Pat Anticancer Drug Discov. 2016;11:322-331.

36. Karousou E, Misra S, Ghatak S, et al. Roles and targeting of the HAS/Hyaluronan/CD44 molecular system in cancer. Matrix Biol. 2017;59:3-22.

37. Huang WY, Lin JN, Hsieh JT, et al. Nanoparticle targeting CD44-positive cancer cells for site-specific drug delivery in prostate cancer therapy. ACS Appl Mater Interfaces. 2016;8:30722-30734.

38. Tran BN, Nguyen HT, Kim JO, et al. Combination of a chemopreventive agent and paclitaxel in CD44-targeted hybrid nanoparticles for breast cancer treatment. Arch Pharm Res. 2017;40:1420-1432.

39. Jeannot V, Mazzaferro S, Lavaud J, et al. Targeting CD44 receptor-positive lung tumors using polysaccharide-based nanocarriers: influence of nanoparticle size and administration route. Nanomedicine. 2016;12:921-932.
40. Zheng X, Zhang F, Zhao Y, et al. Self-assembled dual fluorescence nanoparticles for CD44-targeted delivery of anti-Mir-27a in liver cancer theranostics. Theranostics. 2018;8:3808-3823.

41. Zheng SG, Xu HX, Chen HR. Nano/microparticles and ultrasound contrast agents. World J Radiol. 2013;5:468-471.

42. Zhang X, Servos MR, Liu J. Ultrahigh nanoparticle stability against salt, $\mathrm{Ph}$, and solvent with retained surface accessibility via depletion stabilization. J Am Chem Soc. 2012;134:9910-9913.

43. Moore TL, Rodriguez-Lorenzo L, Hirsch V, et al. Nanoparticle colloidal stability in cell culture media and impact on cellular interactions. Chem Soc Rev. 2015;44:6287-6305.

44. Ma Z, Jia X, Bai J, et al. $\mathrm{MnO} 2$ gatekeeper: an intelligent and $\mathrm{O} 2$-evolving shell for preventing premature release of high cargo payload core, overcoming tumor hypoxia, and acidic H2O2-sensitive MRI. Adv Funct Mater. 2017;27:1604258.

45. Chen $\mathrm{H}$, Tian J, He W, et al. H2O2-activatable and O2-evolving nanoparticles for highly efficient and selective photodynamic therapy against hypoxic tumor cells. $J$ Am Chem Soc. 2015;137:1539-1547.

46. Barch H, Brooks DL, Krutilina R, et al. Abstract 4511: HIF-1-dependent regulation of creatine kinase metabolism promotes breast cancer invasion and metastasis. Cancer Res. 2017;77:4511.

47. Masoud GN, Li W. HIF-1alpha pathway: role, regulation and intervention for cancer therapy. Acta Pharm Sin B. 2015;5:378-389.

48. Ke Q, Costa M. Hypoxia-inducible factor-1 (HIF-1). Mol Pharmacol. 2006;70:1469.

49. Zaharie-Butucel D, Potara M, Suarasan S, et al. Efficient combined near-infrared-triggered therapy: phototherapy over chemotherapy in chitosan-reduced graphene oxide-IR820 dye-doxorubicin nanoplatforms. J Colloid Interface Sci. 2019;552:218-229.

50. Wang J, Guo Y, Hu J, et al. Development of multifunctional polydopamine nanoparticles as a theranostic nanoplatform against cancer cells. Langmuir. 2018;34:9516-9524.
International Journal of Nanomedicine

\section{Publish your work in this journal}

The International Journal of Nanomedicine is an international, peerreviewed journal focusing on the application of nanotechnology in diagnostics, therapeutics, and drug delivery systems throughout the biomedical field. This journal is indexed on PubMed Central, MedLine, CAS, SciSearch ${ }^{\mathbb{R}}$, Current Contents ${ }^{\mathbb{R}} /$ Clinical Medicine, $^{2}$

\section{Dovepress}

Journal Citation Reports/Science Edition, EMBase, Scopus and the Elsevier Bibliographic databases. The manuscript management system is completely online and includes a very quick and fair peer-review system, which is all easy to use. Visit http://www.dovepress.com/ testimonials.php to read real quotes from published authors. 